\title{
Astrocyte-Derived TNF-a Activated Platelets Promote Cerebral Ischemia/Reperfusion Injury by Regulating RIP1/RIP3/AKT Signaling Pathway
}

\section{Wei Li}

Soochow University

\section{Dengping Liu}

The Affiliated Suzhou Science and Technology Town Hospital of Nanjing Medical University Jiaqi Xu

The Affiliated Suzhou Science and Technology Town Hospital of Nanjing Medical University Jun Zha

The Affiliated Suzhou Science and Technology Town Hospital of Nanjing Medical University

\section{Chen Wang}

The Affiliated Suzhou Science and Technology Town Hospital of Nanjing Medical University

\section{Jianzhong An}

The Affiliated Suzhou Science and Technology Town Hospital of Nanjing Medical University

\section{Zhanli Xie ( $\nabla$ zhanlixie1989@njmu.edu.cn )}

The Affiliated Suzhou Science and Technology Town Hospital of Nanjing Medical University https://orcid.org/0000-0001-5047-7737

\section{Shigang Qiao}

The Affiliated Suzhou Science and Technology Town Hospital of Nanjing Medical University

\section{Research Article}

Keywords: Ischemic stroke, TNF-a, platelet, astrocytes, AP-1, RIP1/RIP3/AKT pathway

Posted Date: September 2nd, 2021

DOl: https://doi.org/10.21203/rs.3.rs-849954/v1

License: (c) (i) This work is licensed under a Creative Commons Attribution 4.0 International License. Read Full License 


\section{Abstract}

Ischemic stroke is a type of clinical syndrome caused by disruption of blood flow into the cerebral tissues, and is associated with high disability and mortality rates. Studies have established a pathological role of platelets in cerebral ischemia/reperfusion (I/R) injury, although the underlying mechanisms remain largely unclear. In the present study, we induced I/R in a mouse model via middle cerebral artery occlusion and reperfusion (MCAO/R), and analyzed the transcriptomic profiles of the ipsilateral and contralateral cortices by RNA-seq. We found that cerebral I/R injury induced platelet invasion and accumulation in the cerebral cortex by stimulating TNF-a secretion from the activated astrocytes in the ischemic region. TNF-a enhanced platelet reactivity through the RIP1/RIP3/AKT pathway. Furthermore, inoculation of TNF-astimulated platelets aggravated I/R injury in mice, whereas administration of anti-TNF-a antibodies at the onset of reperfusion alleviated ischemic damage. RNA-seq further showed that AP-1 transcriptionally activated TNF- $a$ in the I/R-injured cortex by directly binding to the promoter region. These findings provide novel insights into the pathological role of platelets induced by reactive astrocyte-derived TNF-a in cerebral I/R injury.

\section{Introduction}

Stroke is among the leading causes of disability and death worldwide. The majority of strokes are caused by cerebral ischemia, and only $\sim 20 \%$ of the cases are the result of primary intracerebral hemorrhage [1]. Ischemic stroke is frequently associated with atherosclerosis, cardiogenic embolism and small vessel occlusion. Most drugs that are currently used to manage ischemic stroke have minimal curative impact along with multiple side effects. Tissue plasminogen activator (tPA), a thrombolytic drug that breaks down the clot, is the only drug approved by the FDA for treating ischemic stroke [2]. However, the therapeutic window of tPA lies within $4.5 \mathrm{~h}$ of the onset of stroke symptoms [3]. Administering the drug outside of this window can result in hemorrhagic transformation, and aggravate tissue damage. Therefore, the mechanisms underlying ischemic stroke have to be elucidated in greater detail to develop more effective therapies.

The pathophysiology of ischemic stroke includes both inflammatory and thrombogenic components [4]. Studies show that excessive platelet aggregation is a hallmark of ischemic stroke [5]. Platelets are critical to hemostasis and thrombosis, and thus modulate innate immunity and tissue homeostasis [6]. However, blocking the final common pathway of platelet aggregation with anti-GPIIb/Illa antibodies did not improve the outcome of acute ischemic stroke, and instead elevated the risk of cerebral ischemia and mortality in a dose-dependent manner $[7,8]$. Thus, cerebral ischemia cannot simply be explained by secondary thrombotic events in microcirculation.

Ischemic stroke causes an immediate local immuno-inflammatory reaction that is characterized by activation of microglia, astrocytes and vascular endothelial cells. The infiltrating inflammatory cells as well as endothelial cells secrete high amounts of adhesion molecules and cytokines [9]. An inflammatory response is both a risk factor and consequence of cerebral infarction [10]. Furthermore, ischemic stroke 
triggers reactive astrocyte aggregation or astrogliosis in the injured marginal region, which is characterized by increased GFAP expression and hypertrophy. Astrocytes are the main inflammatory cells in the cerebral cortex, and release pro-inflammatory factors such as TNF- $a$, IL- $1 \beta$ and IL- 6 under ischemic conditions, which promote brain injury. While astrocytes have been implicated in the resolution of thrombo-inflammation, the role of platelets in this process remains undefined.

TNF-a is a proinflammatory cytokine that primarily secreted by macrophages and monocytes. In addition, platelets can contribute to an acute ischemic episode in the brain by forming homotypic (plateletplatelet) and heterotypic (platelet-leukocyte) aggregates that lead to vascular occlusion, and by secreting inflammatory mediators and vasoconstrictors such as TNF-a [4]. Dai et al found that platelet activation depends on the RIP1/RIP3/AKT signaling pathway [11], and TNF- $a$ activates RIP3 by binding to its receptor (TNF-R) [12]. However, whether TNF-a participates in the pathogenesis of ischemic stroke by regulating platelet reactivity has not been clearly established.

Here, we found that ischemic stroke activated the local astrocytes, which released high amounts of TNF-a that induced platelet aggregation in the ischemic region. Our findings suggest a potentially novel mechanism by which activated platelets induced by reactive astrocyte-derived TNF-a promote cerebral I/R injury.

\section{Materials And Methods}

\section{Ischemic stroke induction by MCAO and reperfusion}

Male C57BL/6J mice weighing 28-32 g were purchased from the Center for Laboratory Animals, Soochow University (Suzhou, China), and housed in a specific pathogen-free facility under ambient conditions. All procedures were performed according to the guidelines of the Institutional Animal Care and Use Committee of Soochow University. Ischemic stroke was induced by middle cerebral artery occlusion (MCAO) with subsequent reperfusion (MCAO/R) as previously described [13]. Briefly, the mice were anesthetized with an intraperitoneal injection (i/p) of $4 \%$ chloral hydrate (350 mg/kg). A 7-0 nylon suture with its tip coated with poly-lysine was inserted into the right common carotid artery and advanced through the internal carotid artery until it occluded the origin of the MCAO. After 90 min of occlusion, cerebral blood flow was reinstated by withdrawing the suture. Body temperature was maintained during and after the surgery within the normothermic range $\left(37 \pm 0.5^{\circ} \mathrm{C}\right)$ by placing the mice on a heating pad (Institute of Biomedical Engineering, CAMS, BME-412A ANIMAL REGULATOR, 308005669) until the effects of anesthesia wore off. The mice were intraperitoneally injected with anti-TNF-a antibody $(20 \mu \mathrm{g} / \mathrm{g}$, $\# 11969$, CST, USA) or vehicle at the onset of reperfusion. Behavioral outcomes were evaluated $24 \mathrm{~h}$ after $\mathrm{I} / \mathrm{R}$ injury and the mice were euthanized with an intraperitoneal injection of pentobarbital sodium. The brains were removed, and the forebrain region was divided into five coronal sections using a mice brain matrix (Harvard apparatus). The sections were stained with 2\% 2,3,5-triphenyltetrazolium chloride (TTC, Sigma) [14], and the infarction volume (\% of the ipsilateral volume) was calculated using the Image $\mathrm{J}$ system. 


\section{Behavioral tests}

Neurological function was evaluated by behavioral tests as previously described [14]. The animals were scored on a 6-point scale for neurological deficits [15] as follows: 0 - no detectable neurological deficits, 1 - ptosis of the eyelid ipsilateral to the occluded MCA side and/or failure to extend ipsilateral forepaw, 2 - persistently walking in large circles toward the ipsilateral side, 3 - persistently walking in small circles and/or rolling over repeatedly towards the ipsilateral side, 4 - lying nearly motionless on the contralateral side, and 5 - death post-recovery. Cylinder test was performed to assess the asymmetric use of forelimbs for postural support. Briefly, the mice were placed inside a plexiglass cylinder (HOOFAN, Wenling, Zhejiang) and forelimb use was observed during their vertical movements along the wall. The final score was calculated as (non-impaired forelimb movement - impaired forelimb movement)/(non-impaired forelimb movement + impaired forelimb movement + movement of both forelimbs) [16]. Twenty movements were recorded during the 10-min test.

\section{Whole transcriptome library preparation and RNA-sequencing}

Total RNA was isolated from the ipsilateral and contralateral cortices $(n=3)$ using the RNeasy Plus Mini Kit (QIAGEN), and the quality was assessed by Agilent 2100 BioAnalyzer according to the manufacturer's instructions. Two micrograms of RNA per sample was used for library construction. Ribosomal RNA (rRNA) was first removed by an Epicenter Ribo-zero rRNA Removal Kit (Epicenter, USA) according to the manufacturer's instructions. Subsequently, strand-specific libraries were generated from the purified RNA by the dUTP method using NEB Next Ultra Directional RNA Library Prep Kit for Illumina (NEB, USA) as per the manufacturer's recommendations. RNA-seq was performed on the Illumina HiSeq 2000 platform, and 100-bp paired-end reads were generated according to the Illumina protocol. The adapter sequences were removed from the raw data, and the individual libraries were converted to the FASTQ format. Sequence reads were aligned to the mouse genome ( $\mathrm{mm} 10)$ with TopHat2 (v2.0.9), and the alignment files were reconstructed with Cufflinks (v2.1.1) and Scripture (beta2). All sequences were annotated using the RefSeq database (build 37.3). The read counts of each transcript were normalized to its length and to the total number of mapped fragments per sample, and were expressed as fragments per kilobase million (FPKM). The differentially expressed genes (DEGs) between the treatment and control groups were screened using adjusted P-value $<0.05$ (Student's $t$ test with Benjamini-Hochberg false discovery rate (FDR) adjustment) as the cutoff. The DEGs were functionally annotated by gene ontology (GO) analysis using the GO-seq R package [17] after correcting the gene length bias was corrected. The pathways significantly associated with the DEGs were identified by Kyoto Encyclopedia of Genes and Genomes (KEGG) analysis using the KOBAS software.

\section{Quantitative real time PCR (qPCR)}

Total RNA was extracted from the ipsilateral and contralateral cortex of three mice using the QIAGEN miRNeasy Mini kit (217004, Qiagen, Germany), and reverse transcribed using the Takara PrimeScript ${ }^{\text {TM }}$ RT Master Mix (RR036A, Takara, Japan). The cDNA templates were amplified by qPCR using the brilliant SYBR green PCR master mixture (4913914, Roche, Switzerland) in LightCycler 480 (Roche, Switzerland). 
The target mRNA expression levels were normalized to that of glyceraldehyde-3-phosphate dehydrogenase (GAPDH) and the relative fold change was calculated by the $2^{-\triangle \Delta C T}$ method. The primer sequences are listed in Supplementary Table S1.

\section{Primary cortical astrocyte culture}

Cortical astrocytes were cultured as previously described [18]. Cerebral cortices were isolated 1- or 2-dayold C57BL/6J mice, mechanically dissociated and digested with trypsin/DNase treatment, and passed through a sterile $40 \mathrm{~lm}$ Nitex mesh. The astrocytes were suspended in DMEM/F12 (1:1) (GIBCO, 11330) supplemented with $10 \%$ heat-inactivated fetal bovine serum (FBS; GIBCO, 10099) and 1\% $100 \mathrm{U} / \mathrm{ml}$ penicillin/streptomycin (Beyotime, C0222), and seeded into culture dishes or plates coated with poly-Llysine. The cells were cultured at $37^{\circ} \mathrm{C}$ in a humidified atmosphere with $5 \% \mathrm{CO}_{2}$.

\section{Oxygen and glucose deprivation and re-oxygenation (OGD/R)}

OGD/R was used to mimic I/R injury in vitro [18]. Briefly, the cells were washed twice with PBS, and cultured in glucose-free DMEM (GIBCO, 11966) under hypoxic conditions $\left(95 \% \mathrm{~N}_{2}\right.$ and $\left.5 \% \mathrm{CO}_{2}\right)$ for $6 \mathrm{~h}$, and then in complete DMEM/F12 under normoxic conditions for $24 \mathrm{~h}$. Anti-TNF- $a$ antibodies $(10 \mathrm{ng} / \mathrm{ml}$, \#11969, CST, USA) or vehicle was administrated during reoxygenation.

\section{Enzyme-linked immunosorbent assay (ELISA)}

TNF-a levels in culture medium, serum and brain homogenates were measured using the mouse (PT512, Beyotime, China) and human (PT518, Beyotime, China) TNF-a ELISA kits according to the manufacturer's instructions. The optical densities of the plates were read at $450 \mathrm{~nm}$ using a spectrophotometer (Bio-Rad Laboratories, Hercules, CA, USA). All steps were performed at room temperature and samples were analyzed in triplicates.

\section{Immunohistochemistry (IHC)}

IHC was performed as previously described [18]. Briefly, the mice were anesthetized with $4 \%$ chloral hydrate $(350 \mathrm{mg} / \mathrm{kg})$ and perfused with PBS and then $4 \%$ paraformaldehyde through the left cardiac ventricle. The brains were removed and fixed in $4 \%$ paraformaldehyde at $4^{\circ} \mathrm{C}$ for $24 \mathrm{~h}$, immersed in phosphate buffer containing $20 \%$ or $30 \%$ sucrose, and sliced into 10 -mm-thick sections using a cryostat. The sections were rinsed with PBS for 15 min, blocked with $1 \%$ bovine serum albumin (BSA) in $0.3 \%$ Triton X-100 for $1 \mathrm{~h}$, and then incubated overnight with mouse anti-CD42d (1:100, AF6990, R\&D, USA), mouse anti-TNF-a (1:100, ab1793, Abcam, USA) and rabbit anti-GFAP (1:500, AB5804, Millipore, USA) antibodies. After washing with PBS, the sections were incubated with Alexa Fluor 488 donkey anti-sheep $\lg G(H+L)(1: 200, A-11015$, Invitrogen, USA), Alexa Fluor 488 sheep anti-mouse $\lg G(H+L)(1: 500$, AB150113, Abcam, USA) and Alexa Fluor 647 donkey anti-rabbit IgG $(\mathrm{H}+\mathrm{L})(1: 500, A B 150063, A b c a m$, USA) secondary antibodies for $1 \mathrm{~h}$ at room-temperature in the dark. The sections were counterstained with 
DAPI (1: 10,000, D9564, Sigma), dried and mounted with coverslips. Images were obtained with a confocal microscope (LSM 710, Carl Zeiss Co. Ltd., Oberkochen, Germany).

\section{Platelet isolation and aggregation}

Mouse blood was diluted 1:5 with an anti-coagulant $\left(65 \mathrm{mM} \mathrm{Na}_{3}\right.$ citrate, $70 \mathrm{mM}$ citric acid, $100 \mathrm{mM}$ dextrose, $\mathrm{pH}$ 4.4), and centrifuged at $900 \mathrm{rpm}$ for $20 \mathrm{~min}$ to obtain the platelet-rich plasma (PRP) [19]. The $\mathrm{PRP}$ was then loaded into Sepharose ${ }^{\mathrm{TM}} 2 \mathrm{~B}$ column, the platelets were eluted using Tyrode's buffer [16]. The gel-filtered platelets were pooled, and the count was adjusted to $2.5 \times 10^{8} / \mathrm{mL}$ in Tyrode's buffer. Platelet aggregation was performed in a ChronoLog aggregometer (Havertown, PA, USA). Aggregation studies were performed using washed platelets prepared and suspended in Tyrode's buffer to which calcium ( $1 \mathrm{mM}$ ) was added as described previously. The percentage of aggregation was calculated using thrombin (1060240001, Sigma, USA) or U46619 (538994, Calbiochem, USA) from the amplitude of the tracings at 5 minutes and normalized to the response of the untreated control within an individual experiment.

\section{Platelet spreading on immobilized fibrinogen}

Chamber slides with microtiter wells were coated overnight with $10 \mu \mathrm{g} / \mathrm{mL}$ human fibrinogen (F4884, Calbiochem, USA) in $0.1 \mathrm{M} \mathrm{NaHCO}_{3}(\mathrm{pH} 8.3)$ at $4^{\circ} \mathrm{C}$. Washed platelets $\left(2 \times 10^{7} / \mathrm{mL}\right)$ were allowed to adhere to and spread on fibrinogen-coated wells at $37^{\circ} \mathrm{C}$ for $2 \mathrm{~h}$ in the presence of thrombin (1060240001, Sigma, USA). The cells were washed once, fixed, permeabilized, and stained with Alexa Fluor 488-conjugated phalloidin (A12379, Life Technologies, USA). The adherent platelets were viewed with an Olympus FluoView FV1000 confocal microscope, and images were acquired. The area traversed by individual platelets was measured using Image $2 x$ software, with pixel number as the unit of size. Ten randomly selected fields from at least three different tests were used for statistical analysis.

\section{Clot Retraction}

Washed mouse platelets $\left(4 \times 10^{8} / \mathrm{mL}\right)$ were resuspended in modified Tyrode's buffer in unused aggregometer tubes and mixed with $150 \mu \mathrm{g} / \mathrm{mL}$ purified human fibrinogen. Clotting was initiated in the presence of $1 \mathrm{U} / \mathrm{mL}$ thrombin at $37^{\circ} \mathrm{C}$ for $60 \mathrm{~min}$. Clot retraction was monitored every $5 \mathrm{~min}$ and photographed, and clot size was measured using Image J2x software.

\section{Immunoblotting}

Protein was extracted from platelets or brain homogenates using RIPA buffer supplemented with protease inhibitor, and quantified using the bicinchoninic acid (BCA) (23227, Thermo, USA) kit. Equal amounts of protein per sample were separated by $8 \%$ SDS-PAGE, transferred to a nitrocellulose membrane, and incubated overnight with antibodies targeting p-RIP1 (Ser166, 1:1000, 53286, CST, USA), 
RIP1 (1:1000, ab202985, Abcam, USA) p-RIP3 (Ser232, 1:1000, ab195117, Abcam, USA), RIP3 (1:1000, ab62344, Abcam, USA), p-AKT (Ser 473, 1:1000, 4060T, CST, USA), AKT (1:1000, 4691S, CST, USA), Fosb ( 1:1000, ab11959, Abcam, USA), Jun (1:1000, ab40766, Abcam, USA), Jund (1:1000, ab181615, Abcam, USA), Fos (1:1000, ab222699, Abcam, USA), Junb (1:1000, 128878, Abcam, USA) and $\beta$-actin (1:5000, A5441, Sigma) in Tris buffered saline containing $0.2 \%$ Tween-20 (TBST) and $5 \%$ nonfat dry milk at $4^{\circ} \mathrm{C}$. After washing with TBST, the membranes were incubated with $1 \mu \mathrm{g} / \mathrm{ml}$ goat anti-rabbit IRDye 800CW or goat anti-mouse IRDye $800 \mathrm{CW}$ (Licor Odyssey, USA). The positive bands were detected using the Odyssey infrared imaging system (LI-COR Biosciences, USA), and the signal intensity was quantified using Image $J$ software and normalized to that of $\beta$-actin.

\section{Luciferase reporter assay}

HEK293T cells (Cell Bank of Chinese Academy of Sciences, Shanghai, China) were cultured in DMEM supplemented with $10 \% \mathrm{FBS}$ (HyClone, Utah, USA) at $37^{\circ} \mathrm{C}$ in a humidified incubator under $5 \% \mathrm{CO}_{2}$ (Thermo Forma Electron Co., Ohio, USA). The $-2000 /-1$ bp region of TNF-a gene was cloned into the luciferase reporter vector (Luc) GV238 into the Xho I and Kpn I sites. HEK 293 T cells were seeded in 96well plates, and co-transfected $12 \mathrm{~h}$ later with $0.1 \mu \mathrm{g}$ TNF-a pro-Luc or empty Luc plasmid (empty-Luc) and $0.1 \mu \mathrm{g}$ Fos-GV230), Jund-GV230, c-Jun-GV230 or empty-GV230 in the presence of Lipofectamine 3000 (Cat\#L3000150, Invitrogen, California, USA). The signals were measured using the dual luciferase reporter assay system (Cat\#E1500, Promega, Wisconsin, USA).

\section{Online database analysis}

Sequencing results of TNF-a gene were analyzed using the BLAT Tool (UCSC Genome Browser, http:// genome-euro.ucsc.edu/). The putative transcription factors of TNF-a were predicted using the PROMO alggen database (http://alggen.Isi.upc.es/cgibin/promo_v3/promo/promoinit.cgi?dirDB=TF_8.3/) within a dissimilarity margin $\leq 5 \%$.

\section{Statistical analysis}

GraphPad Prism 5 was used for statistical analysis. Data are expressed as the mean \pm standard deviation (SD) of at least three independent experiments unless otherwise indicated. One-way ANOVA and Tukey's test were used to compare multiple groups, and two-tailed Student's $t$ test for used for comparing two groups. $P<0.05$ was considered statistically significant.

\section{Results}

\section{TNF-a plays an important role in the pathological process of ischemic stroke}

To determine the transcriptomic profile associated with I/R injury, we sequenced the total RNA isolated from the ipsilateral and contralateral cerebral cortices of mice following MCAO/R. The contralateral undamaged cortices were analyzed as controls. A total of 398 genes were upregulated by 2 -fold and 231 
genes were downregulated in the MCAO/R mice relative to the control (Supplemental Figure 1A), and some random up-regulated genes were validated by qRT-PCR (Supplemental Figure 1B). Functional annotation of these DEGs indicated that I/R injury activated the inflammatory signaling pathway in the cerebral cortex (Fig. 1A). The protein-protein interaction (PPI) network of the DEGs further indicated a key role of TNF- $a$ in the pathological process of I/R injury (Fig. 1B). Consistent with this, TNF-a mRNA expression was significantly up-regulated in brain tissue of mice following MCAO/R (Fig. 1C). In addition, plasma TNF-a levels were markedly higher in stroke patients compared to healthy controls (Fig. 2A), and increased $8 \mathrm{~h}$ post-reperfusion in the MCAO/R model (Fig. 2B-C). Furthermore, primary astrocytes cultured under OGD/R conditions in vitro to mimic l/R injury also exhibited a significant increase in TNF-a levels (Fig. 2D). To ascertain the pathological role of TNF-a in acute ischemic stroke, we injected mice with antiTNF- $a$ antibodies immediately before reperfusion 60 min after MCAO. As shown in Fig. 2E, the volume of the infarct region at $12 \mathrm{~h}$ post-reperfusion was significantly less in mice treated with the anti- TNF-a antibodies compared to the untreated control. Taken together, TNF-a secretion by astrocytes plays an important role in the pathological progression of ischemic stroke, and TNF-a blockade can attenuate brain edema and infarct volume after transient MCAO.

\section{TNF-a aggravates I/R injury by promoting platelet aggregation post-ischemia}

In vitro experiments, we found that TNF- $a$ antibody can prevent platelet aggregation in astrocyte injury model induced by OGD / R (Fig. 3A-B). Integrin allb 33 mediated outside-in signaling can drive clot retraction. The results demonstrated that the average ratio of clot retraction of PRP was significantly more in TNF-a treated astrocyte injury model induced by OGD / R as compared to vehicle treated astrocyte (Fig. 3C). Moreover, TNF-a antibody inhibited platelet spreading in astrocyte injury model induced by OGD / R as compared to vehicle treated astrocyte (Fig. 3F). Therefore, we can know that TNFa released by astrocytes induced by OGD / $\mathrm{R}$ can lead to platelet activation.

Given the role of platelets in the pathogenesis of ischemic stroke, we next analyzed the functional relationship between TNF-a secretion and platelet aggregation in vivo. As shown in Fig. 3E, there was significant platelet accumulation in the cerebral cortex of MCAO/R mice compared to that of the shamoperated controls. Furthermore, cerebral cortex sections stained with antibodies against TNF-a and astrocytes showed that TNF-a released by astrocytes co localized with the platelets, which indicates that TNF-a acts on platelets to regulate the reactivity of platelets (Fig. 3F).

\section{TNF-a alleviated platelet dysfunction induced by cerebral I/R injury through RIP1/RIP3/AKT pathway}

To elucidate the mechanisms by which TNF-a stimulates platelet aggregation in vivo, we performed platelet aggregation induced by a panel of agonists. We found that thrombin and U46619-induced aggregation were increased in PRP of MCAO/R mice. However, TNF-a antibody pretreatment significantly reduced U46619 and thrombin induced platelet aggregation in comparison to the vehicle treated controls, indicating that blocking of TNF-a might exhibit a specific anti-platelet mechanism of action (Fig. 4A-B). Consistent with ablated platelet thrombin, a significantly increased clot retraction was observed in MCAO/R platelets that was recovered by anti-TNF-a addition (Figure 4C). These results suggested that 
clot retraction requires inhibition of TNF-a function. We further investigated role of TNF-a on the platelet activation by analyzing platelet spreading. Mouse platelets were incubated on fibrinogen-coated coverslips and stimulated with poly(PHG). Cerebral ischemia/reperfusion injury can promote platelet spreading, and TNF-a neutralization can reverse this process (Fig. 4D). Thus, these results indicate that cerebral ischemia-reperfusion injury can promote platelet aggregation and activation of integrin outside in signaling, and TNF-a neutralization can reverse this process.

The PI3K-AKT signaling pathway plays an essential role in regulating the second wave of ADP secretion in platelets in response to U46619. We found that TNF-a upregulated the level of p-RIP1 and p-RIP3, and induced AKT phosphorylation (Fig. 5A-C). Taken together, TNF-a released by astrocytes following I/R injury leads to platelet invasion and aggregation in the ischemic area of the cerebral cortex by activating the RIP1/RIP3/AKT pathway.

\section{TNF- $\alpha$ activated platelets aggravate ischemia/reperfusion injury in mice}

To determine whether TNF-a-induced platelet aggregation in the cerebral cortex was the direct cause of ischemic injury, we injected mice with the platelets activated ex vivo with TNF-a (data not shown) prior to inducing MCAO/R. As shown in Fig. 6A-B, the volume of the ischemic region was significantly greater in the activated platelet-treated versus untreated MCAO mice. In addition, the use of right forelimb and the neurological deficit scores were also significantly higher in mice treated with the TNF-a-activated platelets as opposed to the vehicle-treated group (Fig. 6C-D). Thus, invasion and accumulation of the TNF-a activated platelets into the ischemic area of the cortex mediates the pathological progression of stroke.

\section{AP-1 regulated the expression of TNF- $a$ in I/R-injured mice cortex}

To gain further insights into the regulation of TNF-a in I/R-injured cortex, we screened the RNA-seq data for the upregulated transcription factors in the MCAO/R model, and detected significant upregulation in the members of the activator protein (AP)-1 family, including cFos, FosB, cJun, JunB and JunD (Supp Table 2). Further analysis of the cortical tissues also indicated a marked increase in the levels of their mRNA as well as proteins following I/R injury (Fig. 7). We also predicted the TNF-a transcription factors using UCSC website (http://genome.ucsc.edu/) and online bioinformatics tool PROMO alggen database (http://alggen.Isi.upc.es/cgibin/promo_v3/promo/promoinit.cgi?dirDB=TF_8.3/), and found that a significant overlap between the putative transcription factors and those upregulated in the I/R-injured cortex (Fig. 8A). Therefore, we hypothesized that AP-1 is the critical transcriptional regulator of TNF-a during I/R injury. To determine whether TNF-a is indeed the target gene of AP-1, we performed the luciferase report assay to detect binding of Jun, Jund and Fos to the TNF-a promoter. As shown in Fig. $8 \mathrm{~B}-\mathrm{E}$, the luciferase activity of the reporter gene placed under the TNF-a promoter was increased following co-transfection of Jun, Jund and/or Fos expression vectors. Taken together, AP-1 transcriptionally upregulates TNF- $a$ in the mouse cortex following I/R injury by directly binding to its promoter region.

\section{Discussion}


Our findings indicate that ischemic stroke leads to astrogliosis in the cerebral cortex, AP-1 transcriptionally upregulates TNF- $a$ and the TNF- $a$ released by the activated astrocytes induces high platelet reactivity through RIP1/RIP3/AKT pathway. These platelets eventually invade and accumulate in the ischemic area, which aggravates the pathological progression of ischemic stroke (Figure 9).

Inflammation is an independent risk factor for ischemic stroke [20], and high levels of inflammatory cytokines in the ischemic region increase the risk of stroke [21]. Furthermore, previous studies have associated genetic polymorphisms of TNF-a with cerebrovascular disease susceptibility. For instance, Um et al. reported an etio-pathological role of TNF-a-308G/A in cerebral infarction [22]. Another study showed that TNF-a gene variants are a risk factor of ischemic stroke in the Korean population [23]. Consistent with this, our study showed that transcriptome sequencing of the murine cerebral cortex with I/R injury indicated an upregulation of genes involved in the inflammatory signaling pathway. Furthermore, TNFa levels in the cerebral cortex and serum were also significantly increased after MCAO/R, and administration of the anti-TNF- $a$ antibody protected mice from I/R injury. These findings clearly establish a pivotal role of TNF-a in the progression of ischemic stroke.

Astrocytes are the most abundant cells in the cerebral cortex, and the major inflammatory fraction. Ischemic stroke injury can activate astrocytes to produce and release excessive amounts of TNF-a. In addition, studies have correlated the formation of necrotic, procoagulant platelets with adverse outcomes following stroke as well as with increased risk of recurrent stroke [24-27]. Pro-coagulant factors such as thrombin, GPVI and ROS have critical roles in mediating cerebral I/R injury $[7,28,29]$. We showed that the TNF-a released by astrocytes induced platelet invasion into the cerebral cortex of MCAO/R mice, which was alleviated by pre-treatment with TNF-a antibody.

TNF-a is known to activate RIP3 [12], and RIP1 dissociates from complex I and binds RIP3 to form new protein complex necrosome in response to TNF stimulation[30]. RIP3 lies upstream of AKT and regulates platelets activation [31]. Insoluble RIP1, RIP3, and PI3K were increased in the infarct area of mice suffering from MCAO/R injury[32]. Previous studies have reported that necrostatin-1 protects against cerebral injury after acute ischemic stroke by preventing RIP1/RIP3/PI3K-mediated necroptosis[33]. Consistent with these studies, we found that TNF-a by binding to its receptor TNFR triggers the downstream signal transmission and activates RIP3 and RIP1 in ischemic stroke. As an important protein kinase, $\mathrm{PI} 3 \mathrm{~K}$ is well-known to activate its substrate protein AKT and then mediates cell survival and proliferation[34]. In our study, RIP3 activates PI3K by activating AKT - AKT signaling pathway promotes platelet activation. Taken together, TNF-a released by astrocytes promotes platelet aggregation in the cerebral cortex during ischemic stroke by activating the TNFR/RIP1/RIP3/AKT pathway.

The transcription factor AP-1 regulates the expression of multiple inflammatory genes, including TNFa [35]. Mutations in the AP-1 binding site in the TNF-a promoter markedly downregulated the TNF-a gene [36]. Consistent with these reports, we found that AP-1 bound to the TNF-a promoter and enhanced its expression in the I/R-injured mice cortex. Hence, we hypothesized that AP-1 may be a critical transcriptional regulator of TNF-a in MCAO/R-induced cortex. 
To summarize, TNF-a promotes platelet invasion and aggregation in the ischemic cortex, which aggravates the symptoms of stroke. In addition, neutralization of TNF-a is an effective therapeutic strategy against ischemic stroke. We suggest a potentially novel mechanism underlying the protection of platelet in ischemic stroke.

\section{Declarations}

Conflict of interest statement: The authors have declared that no conflict of interest exists.

Availability of data and material: The datasets generated and/or analyzed during the current study are available upon reasonable request.

Authors' contributions: WL, ZLX, and SGQ conceived the project, designed experiments, analyzed the data, and wrote the manuscript. JZA and CW provided critical advice and analyzed the data. WL, DPL, JQX, JZ, ZLX, SGQ performed experiments.

Ethics approval: Animal studies were conducted with protocols approved by the Institutional Animal Care and Use Committee of Soochow University. This study was approved by the ethics committees of Affiliated Suzhou Science \& Technology Town Hospital of Nanjing Medical University Ethics Committee and conducted in accordance with ethical standards of the responsible committee in Affiliated Suzhou Science \& Technology Town Hospital of Nanjing Medical University on human experimentation.

Consent to Participate: All study subjects and/or their relatives gave written informed consent. Informed consent was obtained from participants.

Consent for Publication: All authors have read and approved the submission of the manuscript

Funding: This work was supported by grants Suzhou New District Science and Technology Project (grant no. $2020 Z 003$ to Dr Qiao and grant no. $2020 Z 002$ to Dr Xie) and QNRC2016219 (to Dr. Qiao) from Jiangsu Key Talent Youth Awards in Medicine, GSWS2019092 (to Dr. Qiao) from Gusu Health Youth Talent Awards, and National Natural Science Foundation of China (grant no. 81800128 to Dr Xie).

\section{References}

1. Stegner D, Klaus V, Nieswandt B. Platelets as Modulators of Cerebral Ischemia/Reperfusion Injury. Front Immunol 2019;10:2505.

2. Barthels D, Das H. Current advances in ischemic stroke research and therapies. Biochim Biophys Acta Mol Basis Dis 2020;1866:165260.

3. Fukuta T, Asai T, Yanagida Y, Namba M, Koide H, Shimizu K, Oku N. Combination therapy with liposomal neuroprotectants and tissue plasminogen activator for treatment of ischemic stroke. FASEB J 2017;31:1879-1890. 
4. Jiang RH, Xu XQ, Wu CJ, Lu SS, Zu QQ, Zhao LB, Liu S, et al. The CD40/CD40L system regulates rat cerebral microvasculature after focal ischemia/reperfusion via the mTOR/S6K signaling pathway. Neurol Res 2018;40:717-723.

5. Lim ST, Coughlan CA, Murphy SJ, Fernandez-Cadenas I, Montaner J, Thijs V, Marquardt L, et al. Platelet function testing in transient ischaemic attack and ischaemic stroke: A comprehensive systematic review of the literature. Platelets 2015;26:402-412.

6. Hovhannesyan RA, Hovhannisyan IG. Platelet Aggregation and Interleukins Indicators Impacting the Outcomes of Ischemic Stroke. J Stroke Cerebrovasc Dis 2019;28:2038-2044.

7. Kleinschnitz C, Pozgajova M, Pham M, Bendszus M, Nieswandt B, Stoll G. Targeting platelets in acute experimental stroke: impact of glycoprotein $\mathrm{Ib}, \mathrm{VI}$, and Ilb/Illa blockade on infarct size, functional outcome, and intracranial bleeding. Circulation 2007;115:2323-2330.

8. Adams HP, Jr., Effron MB, Torner J, Davalos A, Frayne J, Teal P, Leclerc J, et al. Emergency administration of abciximab for treatment of patients with acute ischemic stroke: results of an international phase III trial: Abciximab in Emergency Treatment of Stroke Trial (AbESTT-II). Stroke 2008;39:87-99.

9. Lasek-Bal A, Jedrzejowska-Szypulka H, Student S, Warsz-Wianecka A, Zareba K, Puz P, Bal W, et al. The importance of selected markers of inflammation and blood-brain barrier damage for short-term ischemic stroke prognosis. J Physiol Pharmacol 2019;70.

10. Chen JN, Liu YL, Lu MZ, Luo ZR, Luo SH, Yuan P, Gao XL. [Immunological mechanism of tumorigenesis promoted by obstructive sleep apnea hypopnea syndrome]. Zhonghua Jie $\mathrm{He} \mathrm{He} \mathrm{Hu} \mathrm{Xi}$ Za Zhi 2019;42:609-612.

11. Zhang Y, Zhang J, Yan R, Tian J, Zhang Y, Zhang J, Chen M, et al. Receptor-interacting protein kinase 3 promotes platelet activation and thrombosis. Proc Natl Acad Sci U S A 2017;114:2964-2969.

12. Zhang Y, Su SS, Zhao S, Yang Z, Zhong CQ, Chen X, Cai Q, et al. RIP1 autophosphorylation is promoted by mitochondrial ROS and is essential for RIP3 recruitment into necrosome. Nat Commun 2017;8:14329.

13. Li D, Huang B, Liu J, Li L, Li X. Decreased brain K(ATP) channel contributes to exacerbating ischemic brain injury and the failure of neuroprotection by sevoflurane post-conditioning in diabetic rats. PLoS One 2013;8:e73334.

14. Xu M, Yang L, Rong JG, Ni Y, Gu WW, Luo Y, Ishidoh K, et al. Inhibition of cysteine cathepsin B and L activation in astrocytes contributes to neuroprotection against cerebral ischemia via blocking the tBid-mitochondrial apoptotic signaling pathway. Glia 2014;62:855-880.

15. Adhami F, Liao G, Morozov YM, Schloemer A, Schmithorst VJ, Lorenz JN, Dunn RS, et al. Cerebral ischemia-hypoxia induces intravascular coagulation and autophagy. Am J Pathol 2006;169:566-583.

16. Prevost N, Woulfe D, Tanaka T, Brass LF. Interactions between Eph kinases and ephrins provide a mechanism to support platelet aggregation once cell-to-cell contact has occurred. Proc Natl Acad Sci U S A 2002;99:9219-9224. 
17. Young MD, Wakefield MJ, Smyth GK, Oshlack A. Gene ontology analysis for RNA-seq: accounting for selection bias. Genome Biol 2010;11:R14.

18. Sheng R, Zhang LS, Han R, Liu XQ, Gao B, Qin ZH. Autophagy activation is associated with neuroprotection in a rat model of focal cerebral ischemic preconditioning. Autophagy 2010;6:482494.

19. Mou P, Zeng Z, Li Q, Liu X, Xin X, Wannemacher KM, Ruan C, et al. Identification of a calmodulinbinding domain in Sema4D that regulates its exodomain shedding in platelets. Blood 2013;121:4221-4230.

20. Hashimoto H, Kitagawa K, Hougaku H, Shimizu Y, Sakaguchi M, Nagai Y, lyama S, et al. C-reactive protein is an independent predictor of the rate of increase in early carotid atherosclerosis. Circulation 2001;104:63-67.

21. Gu L, Wu G, Su L, Yan Y, Liang B, Tan J, Cai H, et al. TNF-a (-238G/A and -308G/A) gene polymorphisms may not contribute to the risk of ischemic stroke. Int J Neurosci 2016;126:219-226.

22. Um JY, An NH, Kim HM. TNF-alpha and TNF-beta gene polymorphisms in cerebral infarction. J Mol Neurosci 2003;21:167-171.

23. Rubattu S, Speranza R, Ferrari M, Evangelista A, Beccia M, Stanzione R, Assenza GE, et al. A role of TNF-alpha gene variant on juvenile ischemic stroke: a case-control study. Eur J Neurol 2005;12:989993.

24. Kirkpatrick AC, Vincent AS, Dale GL, Prodan Cl. Coated-platelets predict stroke at 30 days following TIA. Neurology 2017;89:125-128.

25. Prodan Cl, Stoner JA, Cowan LD, Dale GL. Higher coated-platelet levels are associated with stroke recurrence following nonlacunar brain infarction. J Cereb Blood Flow Metab 2013;33:287-292.

26. Kirkpatrick AC, Stoner JA, Dale GL, Rabadi M, Prodan Cl. Higher Coated-Platelet Levels in Acute Stroke are Associated with Lower Cognitive Scores at Three Months Post Infarction. J Stroke Cerebrovasc Dis 2019;28:2398-2406.

27. Yao Z, Wang L, Wu X, Zhao L, Chi C, Guo L, Tong D, et al. Enhanced Procoagulant Activity on Blood Cells after Acute Ischemic Stroke. Transl Stroke Res 2017;8:83-91.

28. Chouchani ET, Pell VR, Gaude E, Aksentijevic D, Sundier SY, Robb EL, Logan A, et al. Ischaemic accumulation of succinate controls reperfusion injury through mitochondrial ROS. Nature 2014;515:431-435.

29. Gelderblom M, Leypoldt F, Steinbach K, Behrens D, Choe CU, Siler DA, Arumugam TV, et al. Temporal and spatial dynamics of cerebral immune cell accumulation in stroke. Stroke 2009;40:1849-1857.

30. Li J, McQuade T, Siemer AB, Napetschnig J, Moriwaki K, Hsiao YS, Damko E, et al. The RIP1/RIP3 necrosome forms a functional amyloid signaling complex required for programmed necrosis. Cell 2012;150:339-350.

31. Chen J, De S, Damron DS, Chen WS, Hay N, Byzova TV. Impaired platelet responses to thrombin and collagen in AKT-1-deficient mice. Blood 2004;104:1703-1710. 
32. Zhang Y, Li M, Li X, Zhang H, Wang L, Wu X, Zhang H, et al. Catalytically inactive RIP1 and RIP3 deficiency protect against acute ischemic stroke by inhibiting necroptosis and neuroinflammation. Cell Death Dis 2020;11:565.

33. Deng XX, Li SS, Sun FY. Necrostatin-1 Prevents Necroptosis in Brains after Ischemic Stroke via Inhibition of RIPK1-Mediated RIPK3/MLKL Signaling. Aging Dis 2019;10:807-817.

34. Hu S, Chang X, Zhu H, Wang D, Chen G. PI3K mediates tumor necrosis factor induced-necroptosis through initiating RIP1-RIP3-MLKL signaling pathway activation. Cytokine 2020;129:155046.

35. Flora G, Lee YW, Nath A, Maragos W, Hennig B, Toborek M. Methamphetamine-induced TNF-alpha gene expression and activation of AP-1 in discrete regions of mouse brain: potential role of reactive oxygen intermediates and lipid peroxidation. Neuromolecular Med 2002;2:71-85.

36. Tulbah AS. The potential of Atorvastatin for chronic lung diseases therapy. Saudi Pharm J 2020;28:1353-1363.

\section{Figures}


A
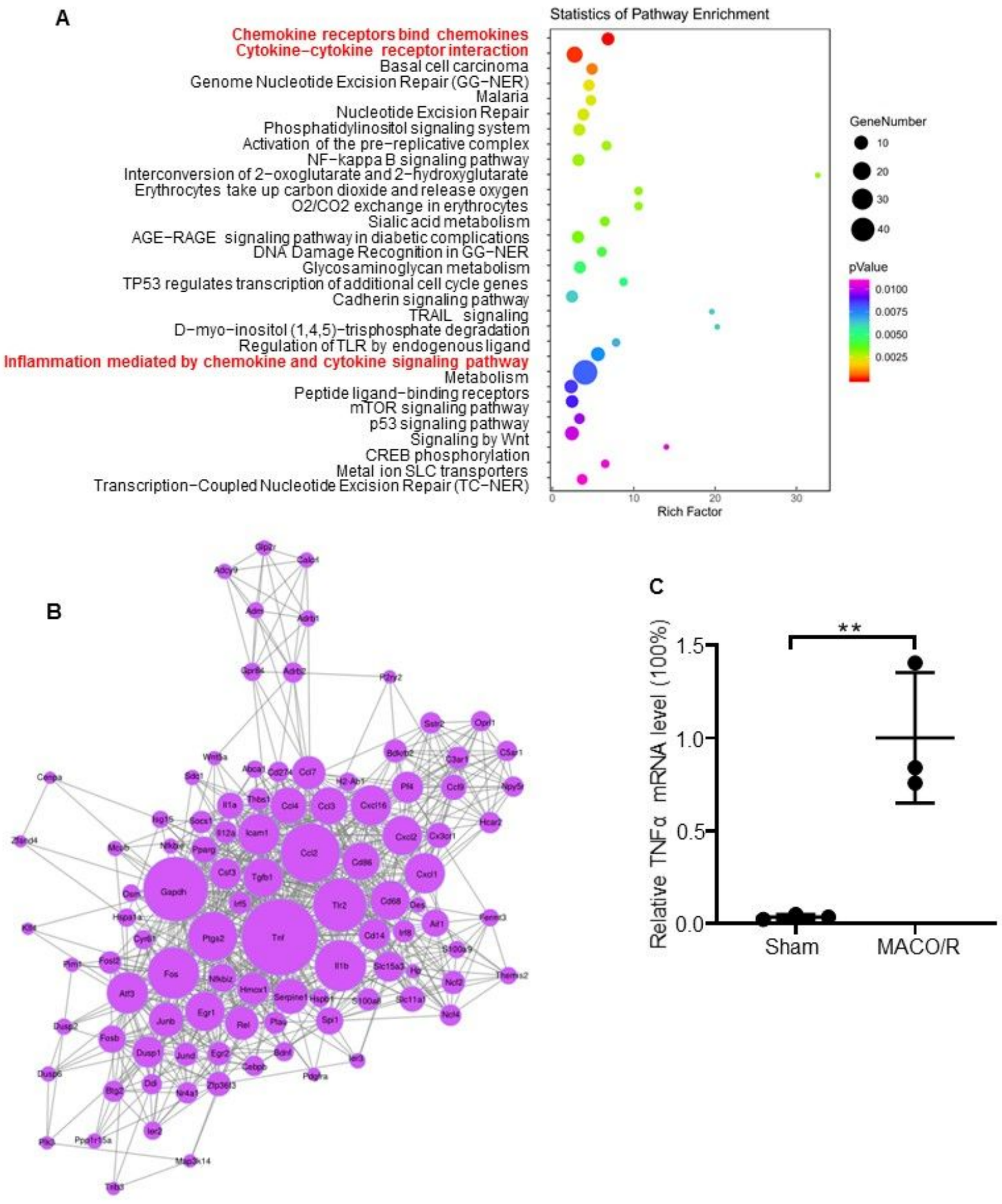

Figure 1

Pathway and protein-protein interaction (PPI) network analysis of up-regulated genes between MCAO/R and control group. (A) Scatter plot showing enriched pathways of up-regulated genes. The size of each circle indicates the number of significantly up-regulated genes corresponding to individual pathways. The enrichment factor was calculated using the number of enriched genes divided by the number of all background genes per pathway. $\mathrm{P}<0.05$ indicates statistical significance. (B) PPI network based on significantly up-regulated genes. The size of each circle indicates the node degree of the corresponding 
gene and grey lines represent interacting partners. (C) Quantitative RT-PCR validation of TNF-a mRNA levels between $\mathrm{I} / \mathrm{R}$ and control groups. The data represent mean $\pm S D$ of two independent experiments, $n$ $=9$ mice/group. *, $\mathrm{P}<0.05 ; * \star, \mathrm{P}<0.01 ; * \star \star, \mathrm{P}<0.001 ; * \star \star \star \mathrm{P}<0.0001$.
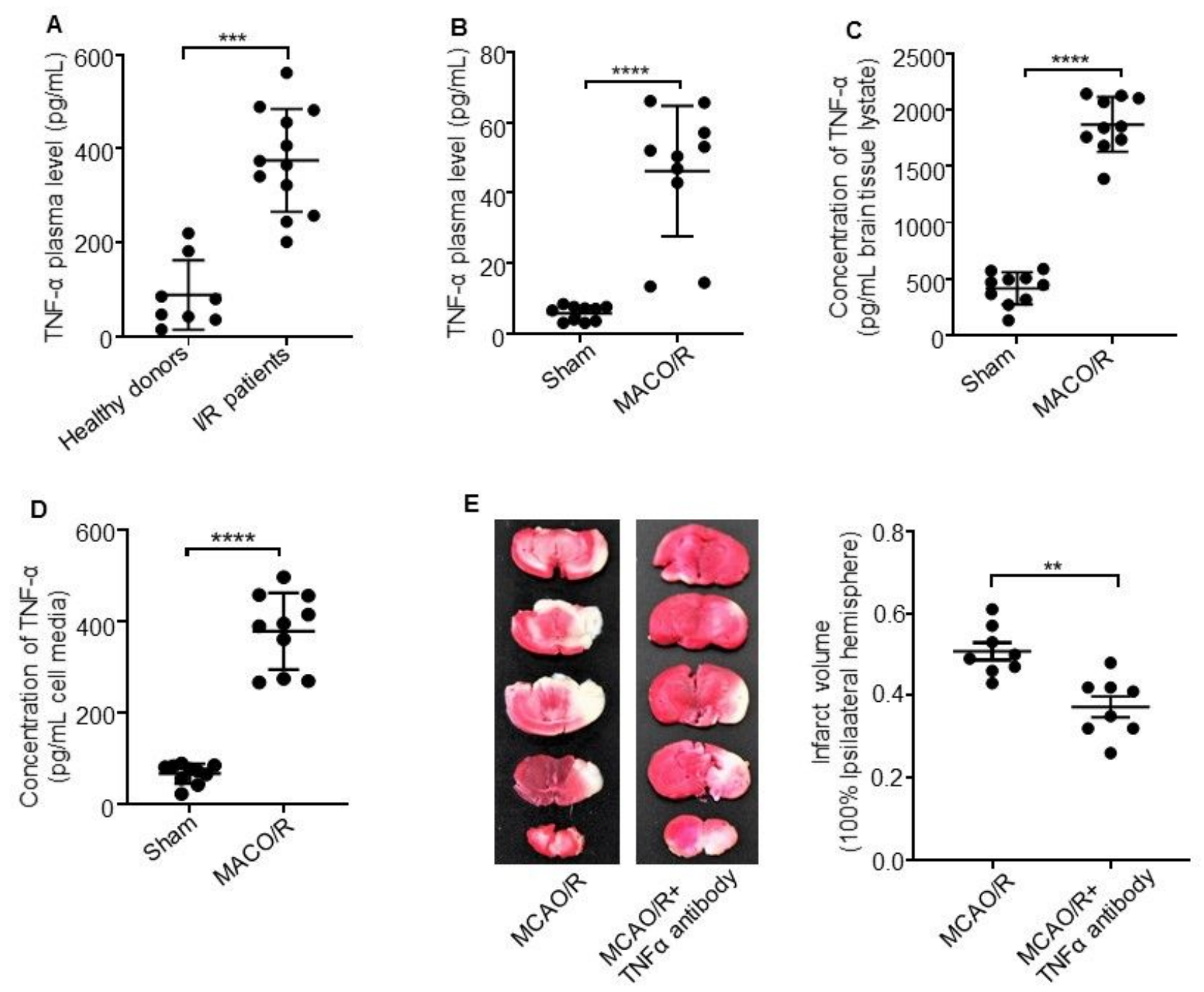

\section{Figure 2}

TNF-a plays an important role in the pathological process of ischemic stroke. (A) TNF-a plasma levels in heathy donors and stroke patients. (B) TNF-a plasma levels in sham-operated and MCAO model mice. (C) TNF-a concentration in the ischemic cortex of sham-operated and I/R mice. (D) TNF-a levels in the media 
of primary cultured astrocytes cultured under normal and OGD/R conditions. (E) Left: representative images of TTC-stained brain slices from MCAO/R mice treated with anti-TNF-a antibodies $(20 \mu \mathrm{g} / \mathrm{g})$ or vehicle at the onset of reperfusion. Right: Infarction volume in the indicated groups. The data represent mean \pm SD of two independent experiments, $\mathrm{n}=9$ mice/group. $*, \mathrm{P}<0.05 ; \star \star, \mathrm{P}<0.01 ; * \star \star, \mathrm{P}<0.001$; $\star \star \star \star P<0.0001$.

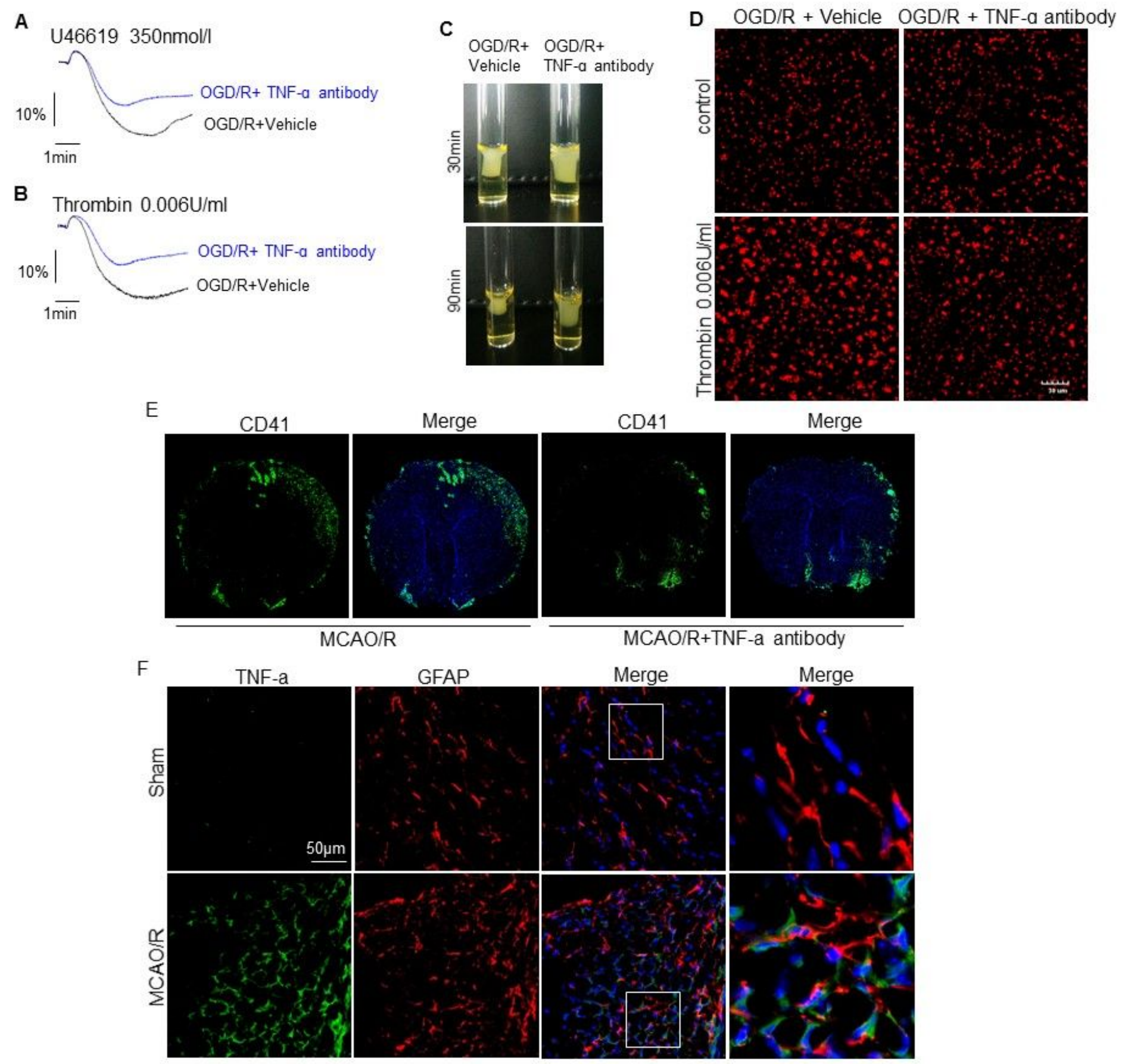

Figure 3 
TNF-a released by astrocytes activates platelets in the ischemic region. (A, B) Aggregation of anti-TNF-a antibody-stimulated platelets in the presence of $\mathrm{U} 46619$ (A) and thrombin (B) at $37^{\circ} \mathrm{C}$. The traces are representative of three independent experiments. Histograms show maximum platelet aggregation under the indicated conditions. The data represent mean $\pm S D$ of two independent experiments, $n=9$

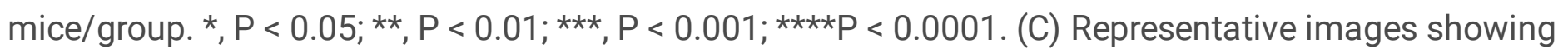
retraction of fibrinogen and thrombin-induced platelet clots pre-incubated with anti-TNF-a antibody (10 $\mathrm{ng} / \mathrm{ml}$ ) or vehicle. (D) Representative images showing the spread of anti-TNF- $\mathrm{a}$ antibody or vehicletreated platelets on fibrinogen-coated wells in the presence of thrombin or vehicle at $37^{\circ} \mathrm{C}$ for $2 \mathrm{~h}$. $(\mathrm{E}, \mathrm{F})$ Representative immunofluorescence images showing CD41+ (red), GFAP+ (red) and TNF- $a+$ (green) cells in the cerebral cortical tissues of mice subjected to MCAO/R and treated with anti-TNF-a antibody or vehicle at the onset of reperfusion. 

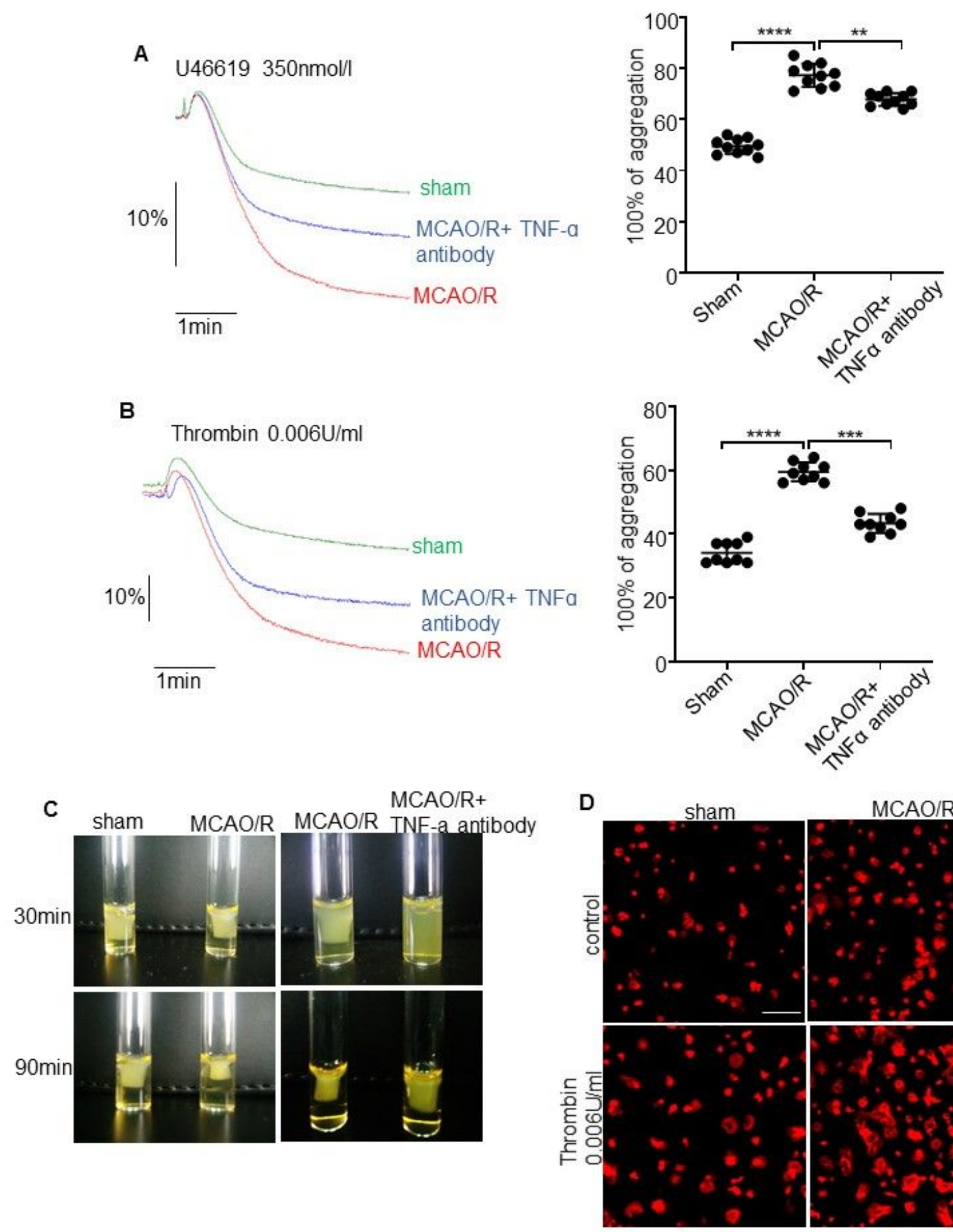

MCAO/R MCAO/R+TNF- $\alpha$ antibody

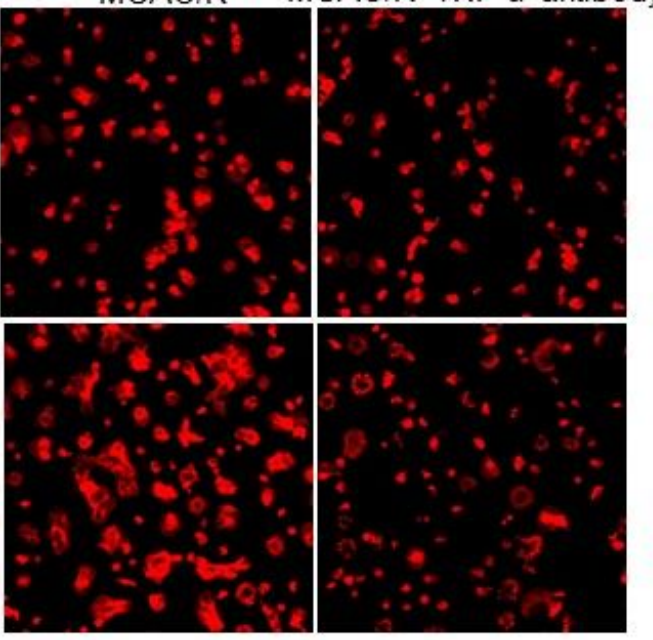

\section{Figure 4}

In vivo neutralization of TNF-a blocks platelet aggregation and integrin signaling. (A, B) Representative images showing aggregation of platelets from sham, I/R and I/R + anti-TNF- $\alpha$ antibody groups in the presence of (A) $\mathrm{U} 46619$ and $(B)$ thrombin at $37^{\circ} \mathrm{C}$. The traces are representative of three independent experiments. Histograms show maximum platelet aggregation under the indicated conditions. The data represent mean $\pm \mathrm{SD}$ of two independent experiments, $\mathrm{n}=9$ mice/group. ${ }^{*}, \mathrm{P}<0.05 ; * \star, \mathrm{P}<0.01 ; * \star \star, \mathrm{P}<$ $0.001 ; * \star * * P<0.0001$. (C) Representative images showing clot retraction of platelets from sham, I/R and 
$\mathrm{I} / \mathrm{R}+$ anti-TNF- $a$ antibody groups in the presence of fibrinogen and thrombin. (D) Representative images showing the spread of platelets from sham, l/R and I/R + anti-TNF- $\alpha$ antibody groups on fibrinogencoated wells in the presence of thrombin or vehicle at $37^{\circ} \mathrm{C}$ for $2 \mathrm{~h}$.
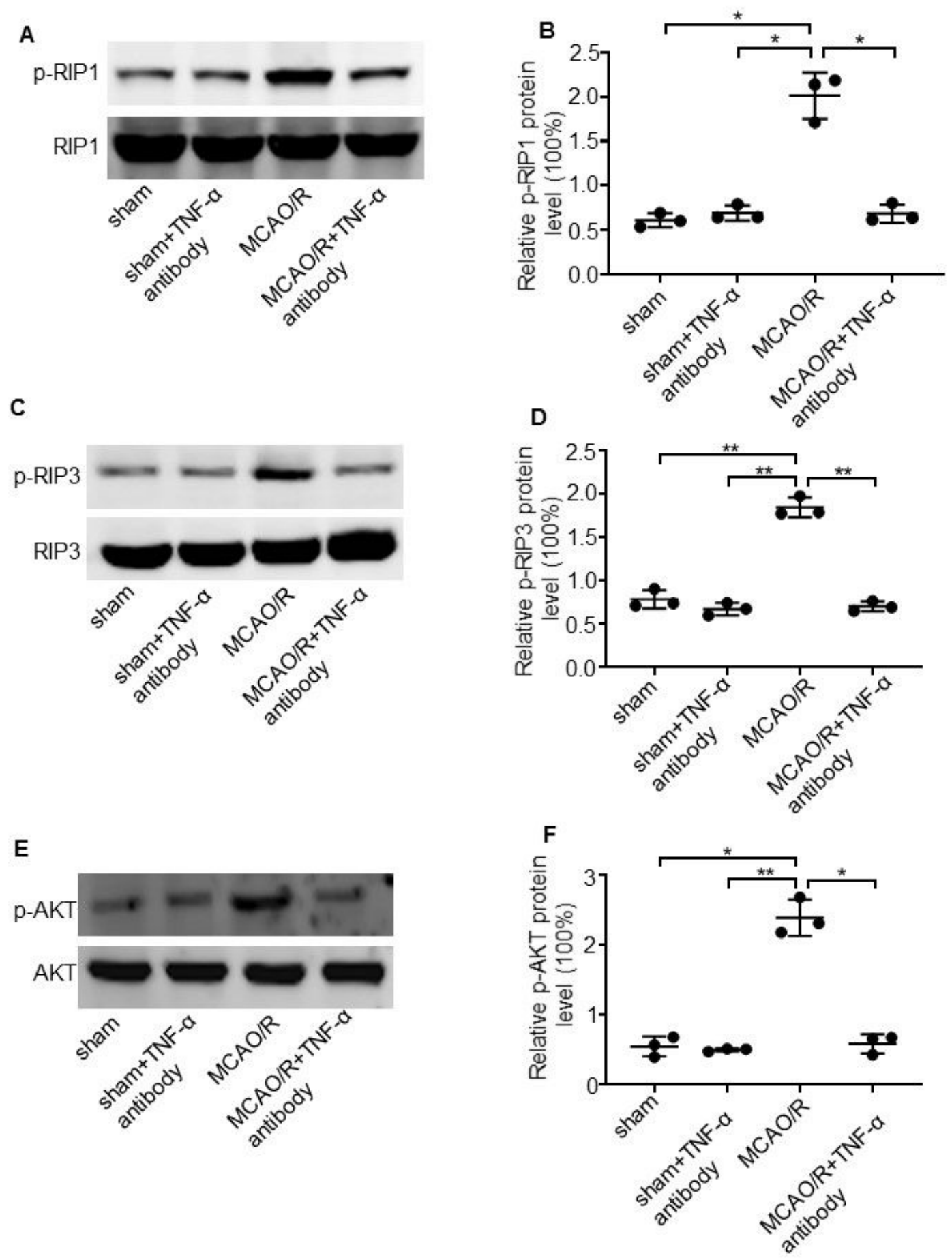

\section{Figure 5}

TNF-a regulates platelet intracellular signaling. Immunoblots and histograms showing levels of $(A, B) p-$ RIP1, (C, D) p-RIP3 and (E, F) p-AKT in the platelets from sham, I/R and I/R + anti-TNF-a antibody groups. 
The data were normalized to loading control total protein. The data represent mean \pm SD of two

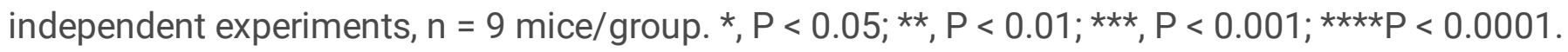

A
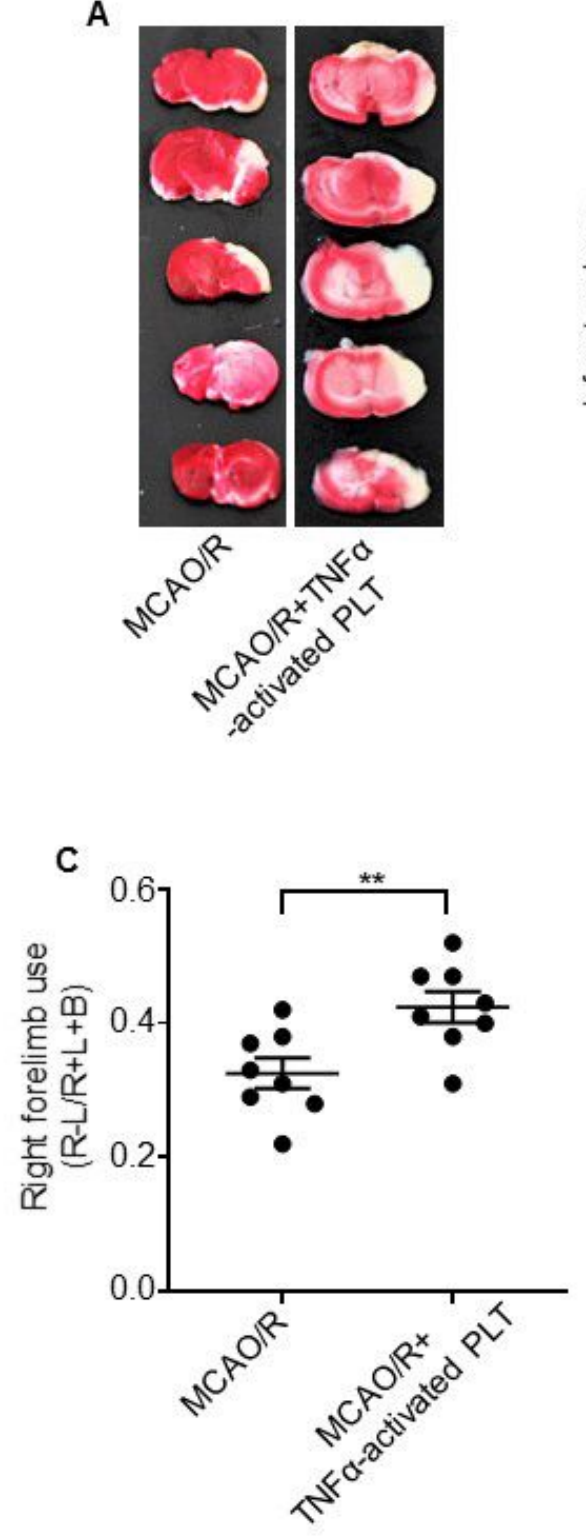

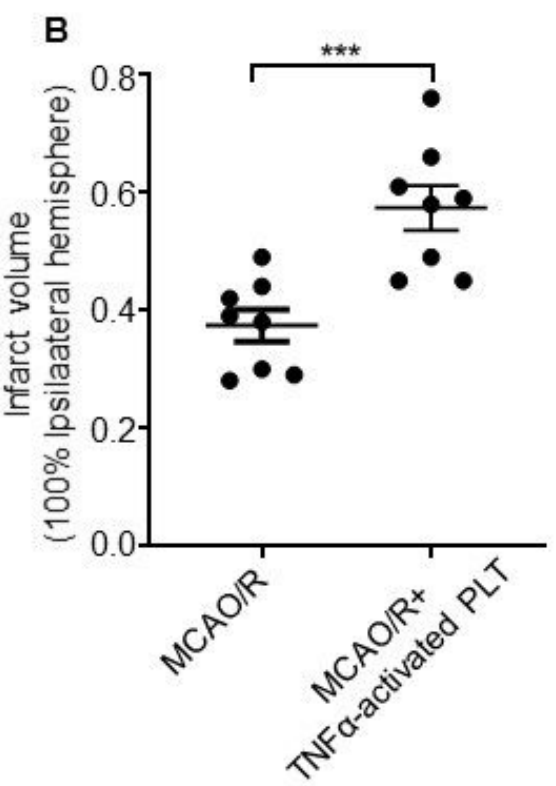

D

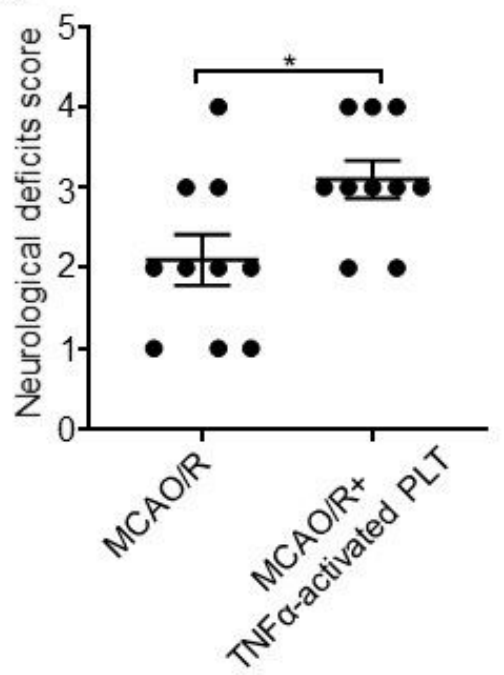

Figure 6

In vivo neutralization of TNF-a reduces the infarction volume and improves neurologic deficits. (A) Representative images of TTC-stained cortical tissues, (B) infarct volume, (C) cylinder test results and (D) neurological scores of mice subjected to MCAO/R treated with anti-TNF- $a$ antibody or vehicle at the onset 
of reperfusion. The data represent mean $\pm \mathrm{SD}$ of two independent experiments, $\mathrm{n}=9$ mice/group. *, $\mathrm{P}<$ $0.05 ; * \star, P<0.01 ; * \star \star, P<0.001 ; * \star \star \star P<0.0001$.
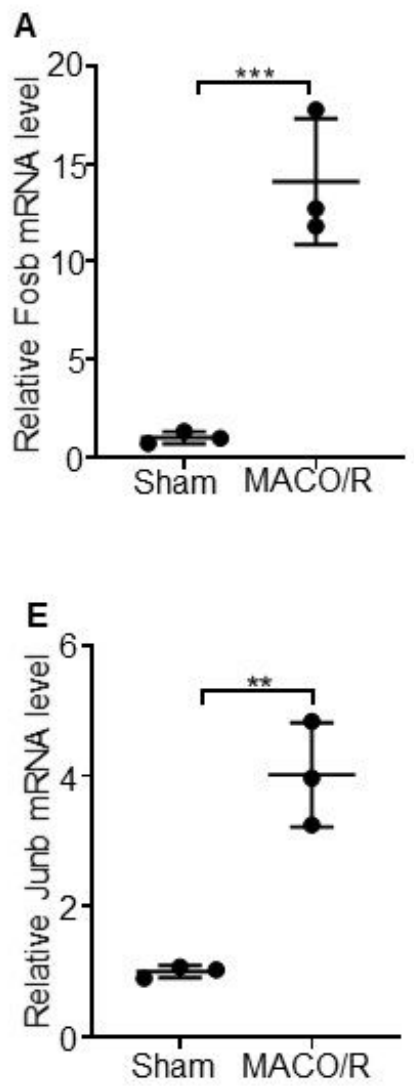

H
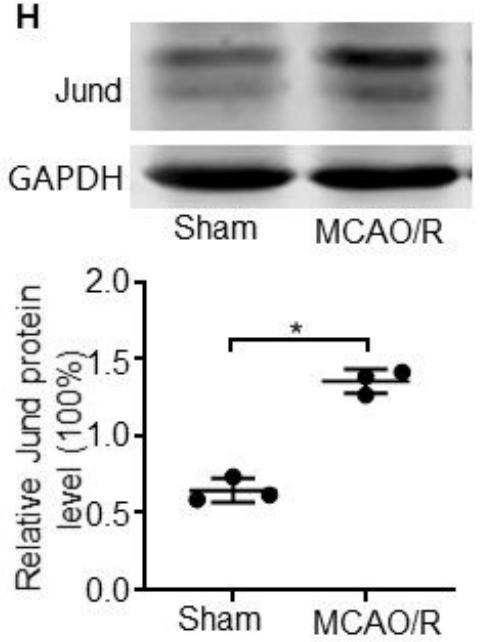

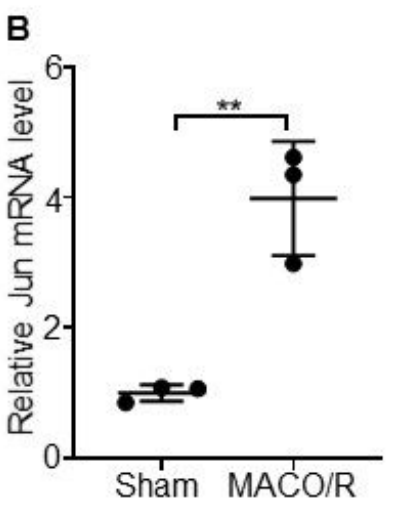

F
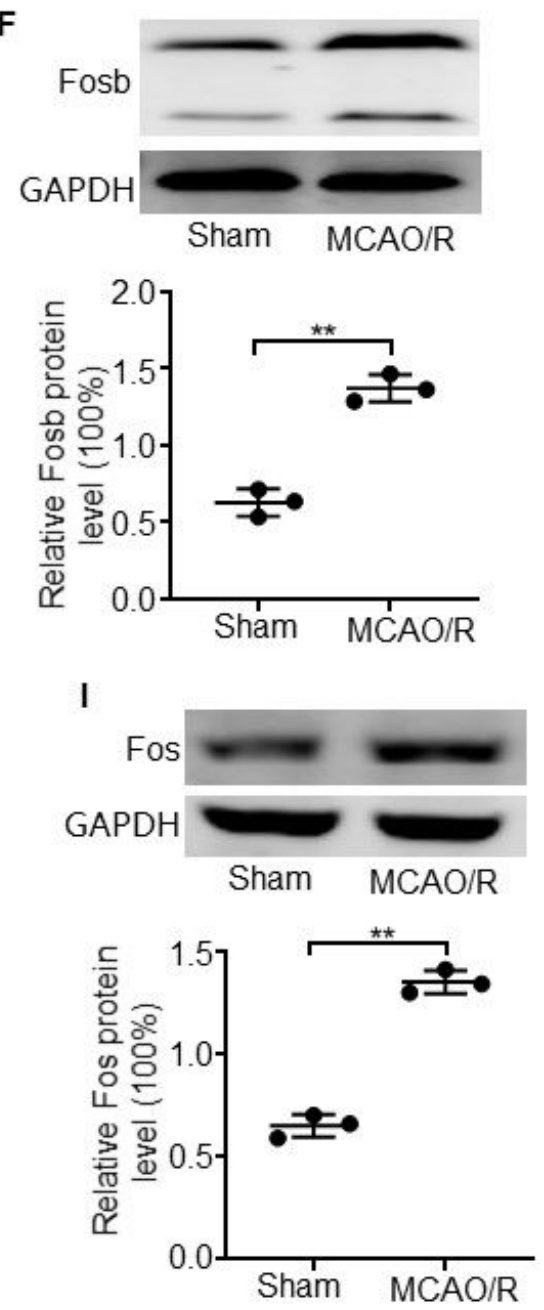

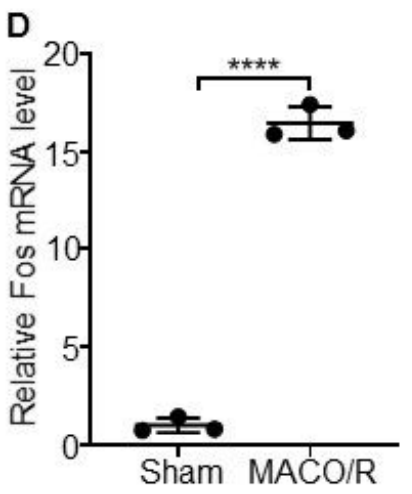

G Jun

GAPDH

Sham MCAO/R
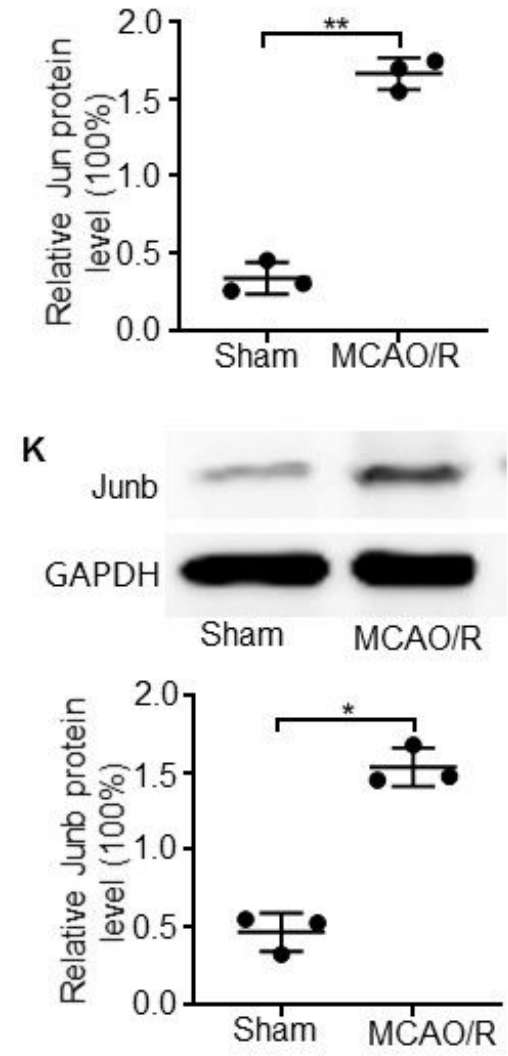

Figure 7

Effect of I/R on AP-1 gene and protein expression in the cerebral cortex. (A) FosB, (B) Jun, (C) cJun, (D) JunD, (E) Fos and (F) JunB mRNA levels I the ipsilateral and contralateral cortices of control and MCAO/R groups. Data is normalized to GAPDH. Fold changes are shown. (F) FosB, (G) Jun, (H) cJun, (I) JunD, (J) 
Fos and $(K)$ JunB protein levels in the indicated groups. The data represent mean \pm SD of two

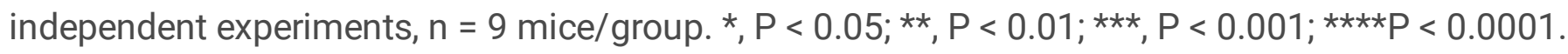
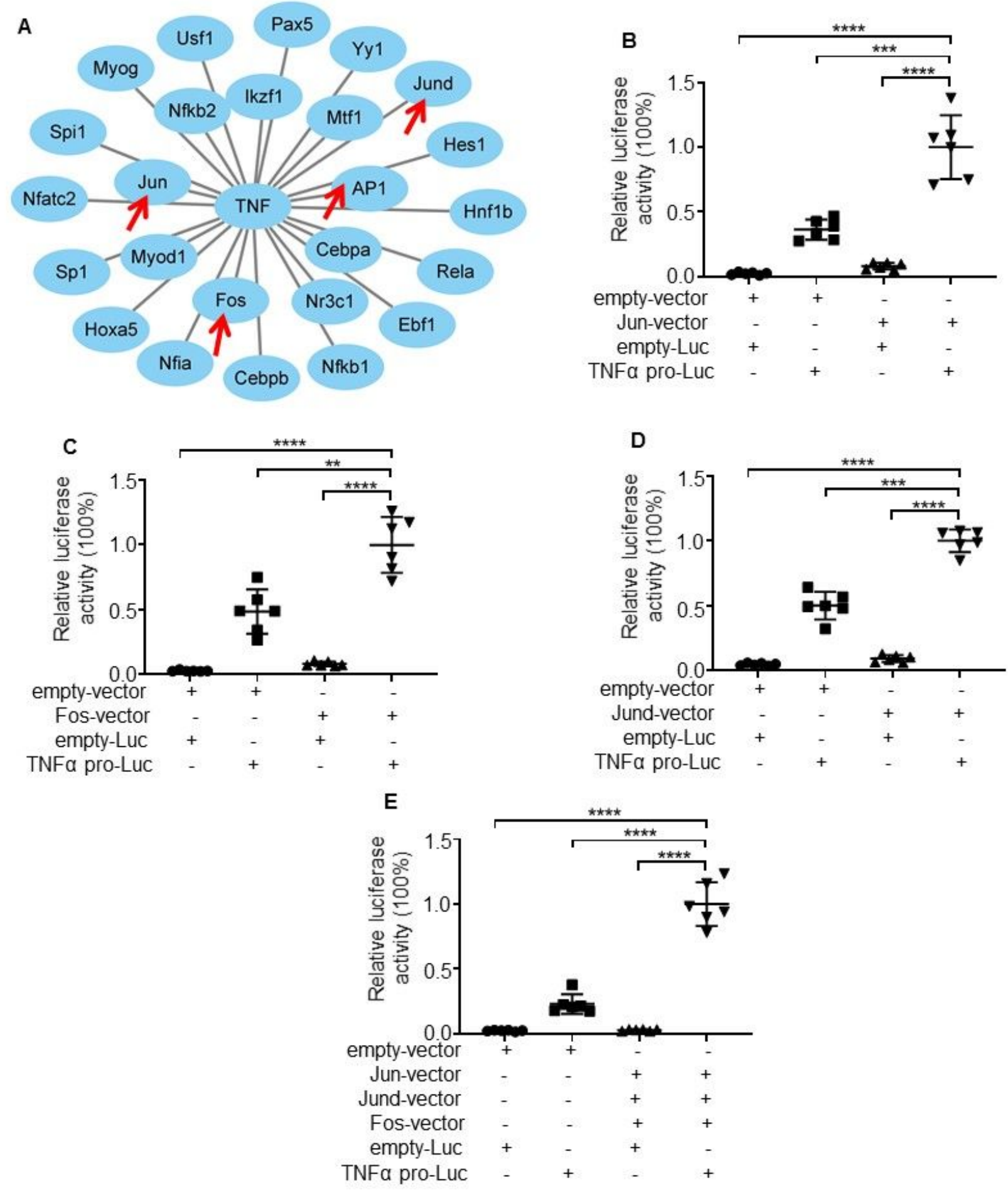

Figure 8

AP-1 regulates the expression of TNF-a. (A) Transcription factors targeting TNF-a predicted using PROMO alggen database within a dissimilarity margin less or equal than 5\%. (B-D) Luciferase activity levels of HEK293T cells co-transfected with TNF-a promoter-Luc reporter and (B) GV230-Jun, (C) GV230-Fos or (D) GV230-JunD or empty vector. (E) Luciferase activity levels of HEK293T cells co-transfected with TNF-a 
promoter-Luc reporter and GV230-vector containing Jun, Fos and JunD, or empty vector as control. The data represent mean $\pm S D$ of two independent experiments, $n=9$ mice/group. ${ }^{*}, P<0.05$; $* \star, P<0.01$; $* \star *$, $\mathrm{P}<0.001 ; * \star \star * \mathrm{P}<0.0001$.

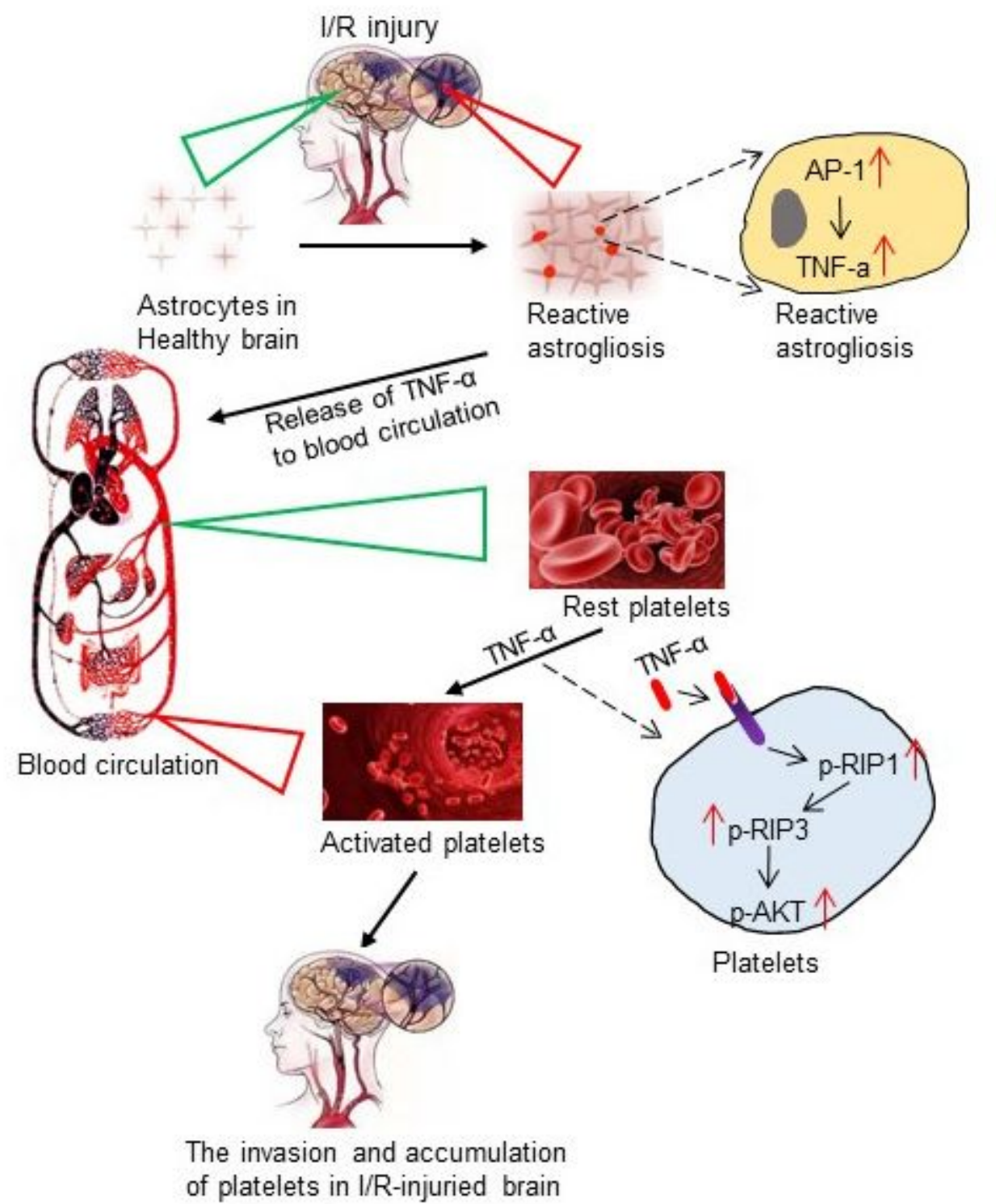

\section{Figure 9}

Schematic diagram of hypothesis that platelets participate in the pathological process of ischemic stroke. Ischemic stroke leads to astrogliosis in the cerebral cortex, AP-1 transcriptionally upregulates TNF$a$ and the TNF-a released by the activated astrocytes induces high platelet reactivity through RIP1/RIP3/AKT pathway. These platelets eventually invade and accumulate in the ischemic area, which aggravates the pathological progression of ischemic stroke.

\section{Supplementary Files}

This is a list of supplementary files associated with this preprint. Click to download. 
- SupplementalFigure1.jpg

- SupplementalFigure2.jpg

- SupplementalInformationFinal.docx

- supplementaltable1.xlsx

- supplementaltable2.xls 